\title{
Effect of HIP Treatment on Microstructure and Fatigue Strength of Selectively Laser Melted AlSi10Mg
}

\author{
Wolfgang Schneller ${ }^{1, *(\mathbb{D})}$, Martin Leitner ${ }^{1} \mathbb{D}$, Sebastian Springer ${ }^{1}$, Florian Grün ${ }^{1} \mathbb{D}$ and \\ Michael Taschauer ${ }^{2}$ \\ 1 Department Product Engineering, Chair of Mechanical Engineering, Montanuniversität Leoben, \\ 8700 Leoben, Austria; martin.leitner@unileoben.ac.at (M.L.); sebastian.springer@unileoben.ac.at (S.S.); \\ florian.gruen@unileoben.ac.at (F.G.) \\ 2 Pankl Systems Austria GmbH, 8605 Kapfenberg, Austria; michael.taschauer@pankl.com \\ * Correspondence: wolfgang.schneller@unileoben.ac.at; Tel.: +43-3842-402-1451
}

Received: 15 December 2018; Accepted: 29 January 2019; Published: 1 February 2019

\begin{abstract}
This study shows the effect of hot isostatic pressing (HIP) on the porosity and the microstructure, as well as the corresponding fatigue strength of selectively-laser-melted (SLM) AlSi10Mg structures. To eliminate the influence of the as-built surface, all specimens are machined and exhibit a polished surface. To highlight the effect of the HIP treatment, the HIP specimens are compared to a test series without any post-treatment. The fatigue characteristic is evaluated by tension-compression high cycle fatigue tests under a load stress ratio of $R=-1$. The influence of HIP on the microstructural characteristics is investigated by utilizing scanning electron microscopy of micrographs of selected samples. In order to study the failure mechanism and the fatigue crack origin, a fracture surface analysis is carried out. It is found that, due to the HIP process and subsequent annealing, there is a beneficial effect on the microstructure regarding the fatigue crack propagation, such as Fe-rich precipitates and silicon agglomerations. This leads, combined with a significant reduction of global porosity and a decrease of micro pore sizes, to an improved fatigue resistance for the HIPed condition compared to the other test series within this study.
\end{abstract}

Keywords: additive manufacturing; SLM; AlSi10Mg; fatigue strength; HIP; porosity

\section{Introduction}

Additive manufacturing (AM) offers the possibility to manufacture complexly-shaped and topographically-optimized components [1-5]. Therefore, powder bed-based AM is contemplated to find application in various fields such as aviation, automotive, and biomedical engineering [6]. Estimations state that $55 \%$ of all failures in aeronautic engineering and, generally speaking, about $90 \%$ of all engineering failures are caused by a fatigue-related damage mechanism [7,8]. Hence, it is of upmost importance to investigate and understand the fracture mechanisms and fatigue characteristics, to assess properly, as well as safely the material qualifications. It is crucial to take account of the interaction between the microstructure, internal defects, and fatigue resistance $[9,10]$.

Inner imperfections like unmolten areas or bonding errors between melt-pool borders and pores are mostly responsible for fatigue failures concerning AM components. It is necessary to control the distribution and extension of such cavities, as they are preferable spots for fatigue crack initiation [11,12]. Given the fact that in the case of cast aluminum alloys, hot isostatic pressing (HIP) significantly decreases the volume fraction of porosity with only minor changes of microstructural features, leading to a considerable increase of fatigue strength, an appropriate post-treatment may be 
beneficial to AM parts, as well [13-16]. One can find that due to the extremely fine microstructure of selectively-laser-melted (SLM) parts, an HIP treatment above the solubility temperature of AISi10Mg leads to microstructural coarsening because of the dissolving of grain boundaries. This results in a reduced fatigue resistance, although the porosity is significantly lower $[8,17]$. To take advantage of the beneficial effect of HIP on the porosity, the changes within the microstructure cause the necessity of quenching and a subsequent age hardening process to counteract these negative effects [18]. The exact HIP parameter was determined incorporating the knowledge of the specimen manufacturer with the aim of reducing the amount of porosity in order to improve the fatigue behavior.

For this reason, the fatigue strength of the HIP-treated specimen at a commonly-used temperature for solution annealing followed by low temperature annealing as heat treatment was investigated. Besides their fatigue resistance, the local material properties, such as porosity and microstructure, were analyzed and compared to specimens without any post-treatment, denoted as the as-built condition.

\section{Materials and Methods}

The chemical composition of the utilized AlSi10Mg powder, shown in Table 1, is given by the manufacturer specification and corresponds to the standard DIN EN 1706:2010 [19].

Table 1. Chemical composition of the additive manufacturing (AM) powder by weight \%.

\begin{tabular}{ccccccc}
\hline Material & Si & Fe & Cu & Mn & Mg & Al \\
\hline AlSi10Mg & $9.0-11.0$ & 0.55 & 0.05 & 0.45 & $0.20-0.45$ & Balance \\
\hline
\end{tabular}

Specimens were fabricated using an EOS M290 system with a Yb fiber laser, a power of $400 \mathrm{~W}$, and a beam diameter of $100 \mu \mathrm{m}$. All specimens were built in the vertical direction with a certain machining allowance in order to remove subsequently the as-built surface and eliminate surface-related effects. The structures were manufactured according to the standard parameter set given by the system and powder manufacturer EOS. Following the built process, hot isostatic pressing was performed applying a temperature higher than $500{ }^{\circ} \mathrm{C}$ and a pressure of above $100 \mathrm{MPa}$ with a holding time of at least two hours followed by quenching under constant pressure. Low temperature annealing over a certain time period was conducted afterwards. Subsequent to the heat treatment, the specimens were processed to the final geometry by turning and polishing. A CAD drawing with the detailed specimen geometry and dimensions is shown in Figure 1. The shape of the specimens was designed to show a homogeneous stress distribution over the cross-section with a stress concentration factor as low as possible due to the narrowing within the testing section, corresponding to no common standard.

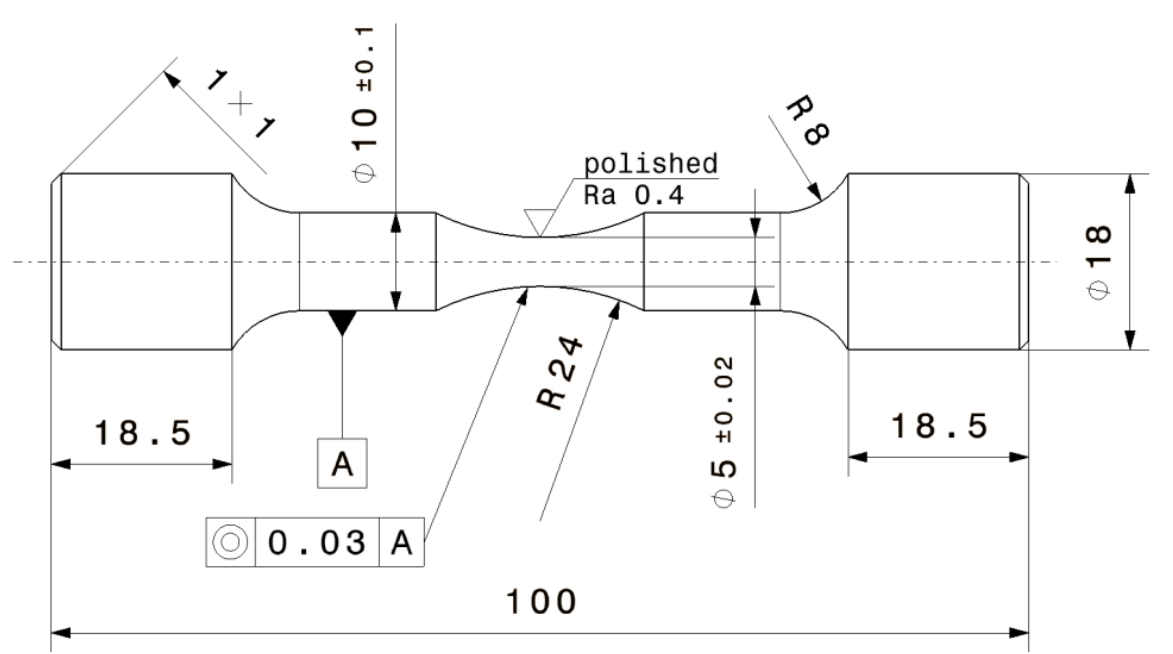

Figure 1. CAD drawing of the specimen geometry for the high cycle fatigue test. 
The specimens are fatigue tested at a load stress ratio of $R=-1$ on a RUMUL Mikrotron resonant testing rig with a frequency of about $106 \mathrm{~Hz}$. Collets were used for gripping in order to clamp the specimen at both ends. The abort criterion was defined either as total fracture or as run-out at $1 \times 10^{7}$ load cycles. Run-outs were reinserted at higher stress levels to obtain more data in the finite life regime, conservatively assuming pre-damaging at stress levels lower than the endurance limit [20]. For each test series, respectively with and without HIP treatment, nine specimens were manufactured and tested.

\section{Results and Discussion}

\subsection{Effect of HIP Treatment on the Microstructure}

HIP treatment at high temperature with considerably high pressure leads to significant microstructural differences compared to the as-built condition; hence, the effect on the material was investigated in detail. To characterize the microstructure after HIP and heat treatment, SEM images, taken with a Carl Zeiss EVO MA 15 microscope, of the post-processed condition were evaluated. In Figure 2, one can clearly see Fe-rich precipitates and Si particles, which were also detected in [21]. Silicon crystals were precipitated at the grain boundaries during the HIP treatment above the solubility temperature, and they grew to their respective size during low temperature annealing [22-25]. Microstructural features like silicon agglomerations and needle-shaped, Fe-rich precipitates obstructed a propagating fatigue crack and, therefore, generally improved the resistance against fatigue crack growth. Such microstructures favor crack deflection and energy dissipation at the crack tip. Hence, the long crack growth was decelerated, whereby the fatigue strength was enhanced $[17,26]$.

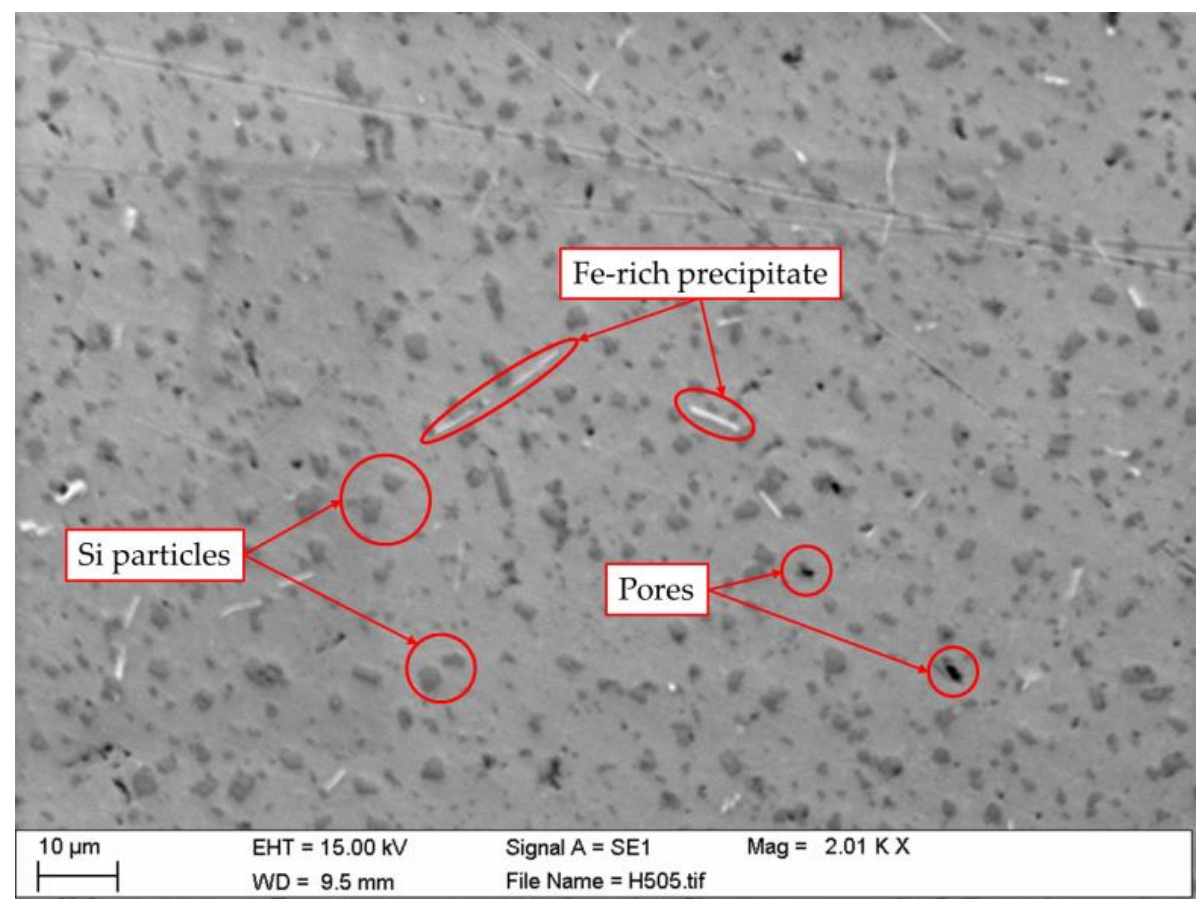

Figure 2. Microstructure after HIP and subsequent heat treatment.

Comparing the microstructure of the as-built condition (Figure 3a) to the microstructure after the post-treatment (Figure $3 \mathrm{~b}, \mathrm{c}$ ), appreciable differences regarding the porosity we observed. For that reason, these figures have the same magnification and scale. A larger magnification image is depictured in Figure 3d, which reveals a circular shape of the observed micro-porosity. One can see that the amount of porosity and the maximum extension of pores have significantly decreased. Additionally, after the post-treatment, melt-pool boundaries completely vanished. The aforementioned Fe-rich precipitates 
and Si-crystals were formed within the microstructure. Throughout the annealing, the Si-particles grew at Si-rich cellular boundaries, and finally, grain boundaries were no longer clearly visible at this stage due to the heat influence [23]. The comparison between backscatter images before (Figure 3a) and after (Figure 3b) HIP treatment highlights this microstructural change.

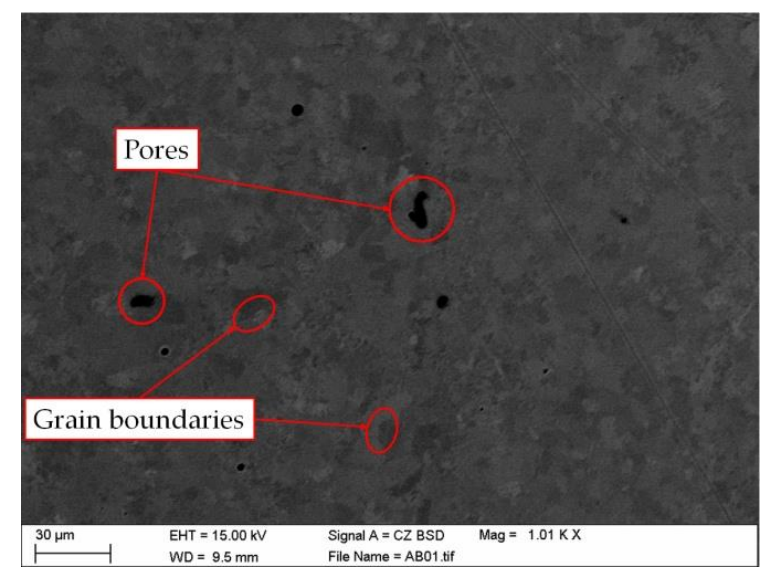

(a)

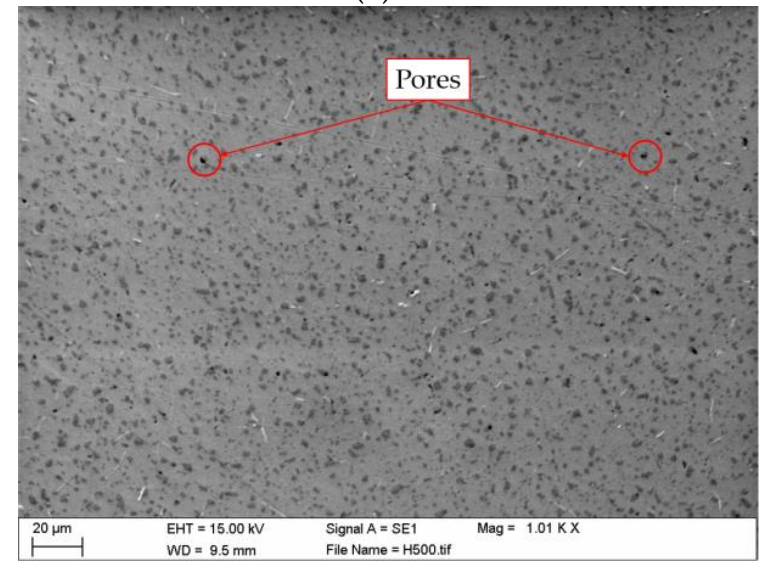

(c)

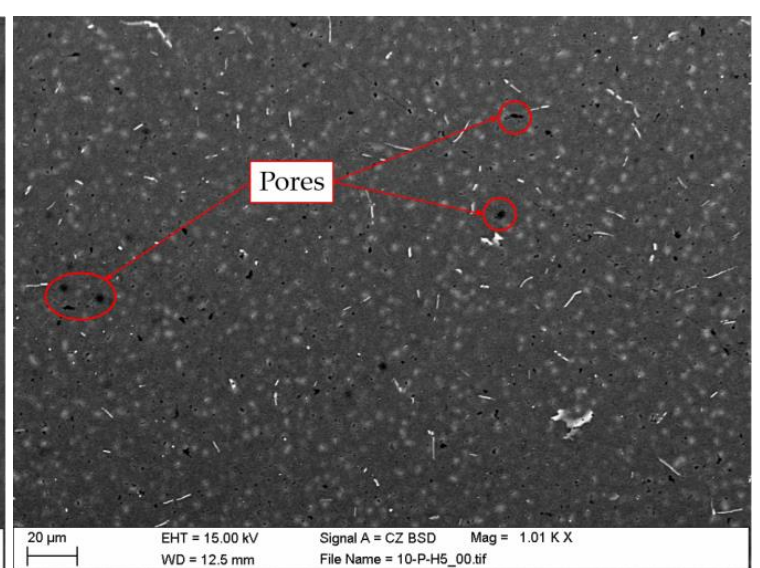

(b)

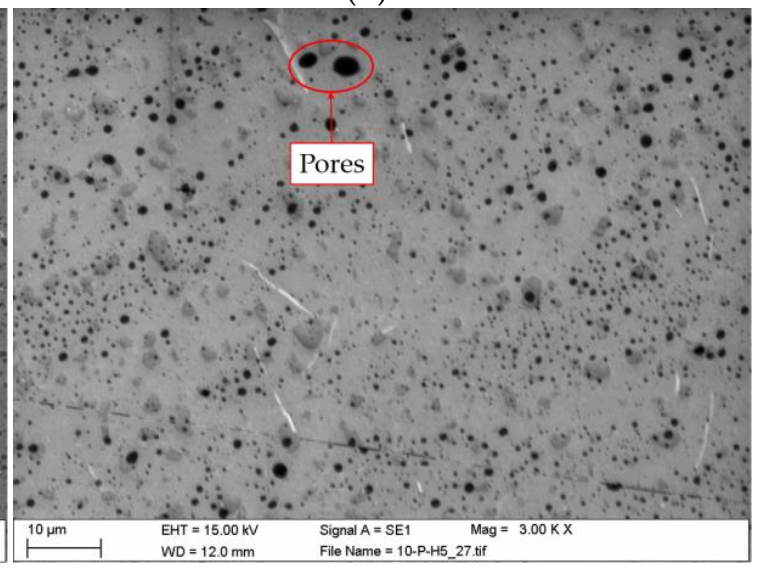

(d)

Figure 3. Microstructure (a) before and (b-d) after post-treatment.

\subsection{Fatigue Tests}

The fatigue test results are presented in Figure 4. The dashed line with square marks represents the data for the as-built series. The full line with triangle markings shows the data for the HIP condition. Within the finite life region, the specimen was tested at several load levels with a certain incrementation. The evaluation of the SN-curve in the finite life region is based on the ASTM E739 standard [27]. The high cycle fatigue strength at $1 \times 10^{7}$ load-cycles was statistically evaluated by applying the $\arcsin \sqrt{ } \mathrm{P}$-transformation procedure given in [28]. Run-outs were reinserted at higher stress levels in order to obtain additional data within the finite life region. The results were normalized to the nominal ultimate tensile strength (UTS) of the additively-manufactured material without any post-treatment, given by the powder manufacturer [29]. The peak load level was set at about $35 \%$ of the UTS, which was well below the yield strength according to the powder manufacturer, to ensure testing within the linear-elastic region of the material and obtain reasonable results regarding endured load cycles. The results revealed that the HIP test series provided an increase of the high cycle fatigue strength of about $14 \%$ considering a survival probability of $\mathrm{P}_{\mathrm{S}}=50 \%$. The scatter band between $10 \%$ and $90 \%$ survival probability, referring to the stress amplitude, minorly decreased for the HIP condition compared to the as-built condition. Furthermore, the slope in the finite life region was less steep for the HIP condition. The fatigue test results are summarized in Table 2. 


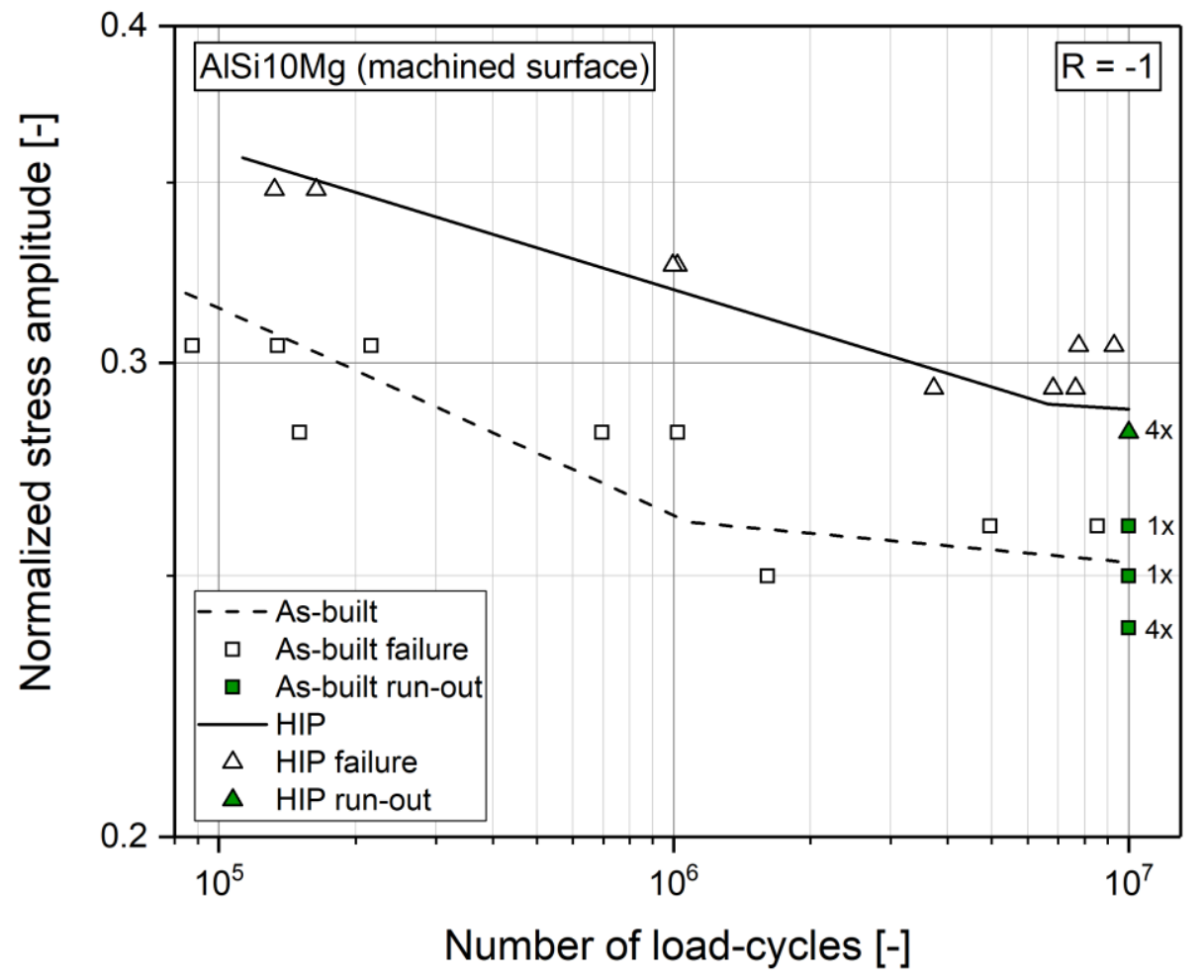

Figure 4. SN-curves for the as-built and HIP condition.

Table 2. Statistically evaluated SN-curve parameters for both test series.

\begin{tabular}{ccccc}
\hline Condition & $\begin{array}{c}\text { Normalized Fatigue } \\
\text { Strength }\left(\mathbf{P}_{\mathbf{S}}=\mathbf{5 0} \%\right)\end{array}$ & Difference & $\begin{array}{c}\text { Slope in the Finite } \\
\text { Life Region }\end{array}$ & $\begin{array}{c}\text { Scatter Band in the } \\
\text { Finite Life Region }\end{array}$ \\
\hline As-built & 0.253 & Basis & 12.99 & $1: 1.15$ \\
HIP-treated & 0.288 & $+14 \%$ & 19.37 & $1: 1.06$ \\
\hline
\end{tabular}

\subsection{Metallographic and Fracture Surface Analysis}

In order to evaluate the decrease in porosity, the average maximum pore extension, as well as the equivalent circle pore diameter, several micrographs of the two conditions were investigated. Figure 5 a shows an example of the as-built condition, whereas Figure $5 b$ is taken from the microsection of an HIP-treated specimen. All pictures of micrographs and fracture surfaces were recorded with a KEYENCE VHX-5000 light optical digital microscope. The microsections were prepared only by polishing and received no additional etching. Dependent on the polished surface and the image post-processing, different lighting options and angles were necessary. This was the reason why the as-built specimen in Figure 5a (ring-lighting) appears blue and shows a different texture, e.g., visible melting tracks and laser scanning strategy, than the HIP sample in Figure 5b (coaxial lighting). In order to determine the amount of porosity, image processing tools were utilized. At first, the images were converted to binary pictures with a certain threshold to ensure that the microsection of the specimen area appeared white while pores appeared black. Secondly, the embedding material was subtracted from the image. In the end, the separated pores, as well as the porosity, which is the ratio of specimen area to pore area, could easily be evaluated. The outcome is presented in Figure $6 \mathrm{a}-\mathrm{c}$ and summarized in Table 3. The results were again normalized to the as-built condition to highlight the differences between the two test series. The results maintained that the HIP samples possessed a significant lower level of porosity $(-64 \%)$, a decreased maximum pore extension $(-22 \%)$, as well as an equivalent circle diameter $(-11 \%)$. 


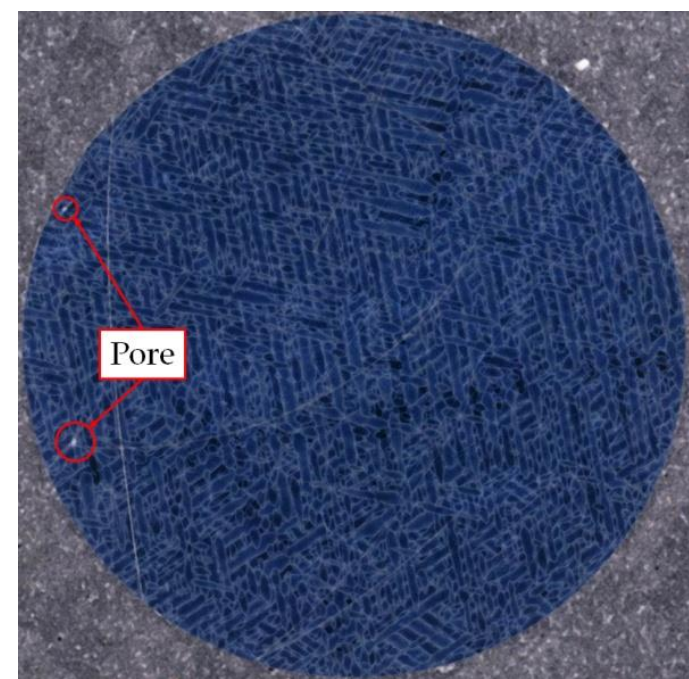

(a)

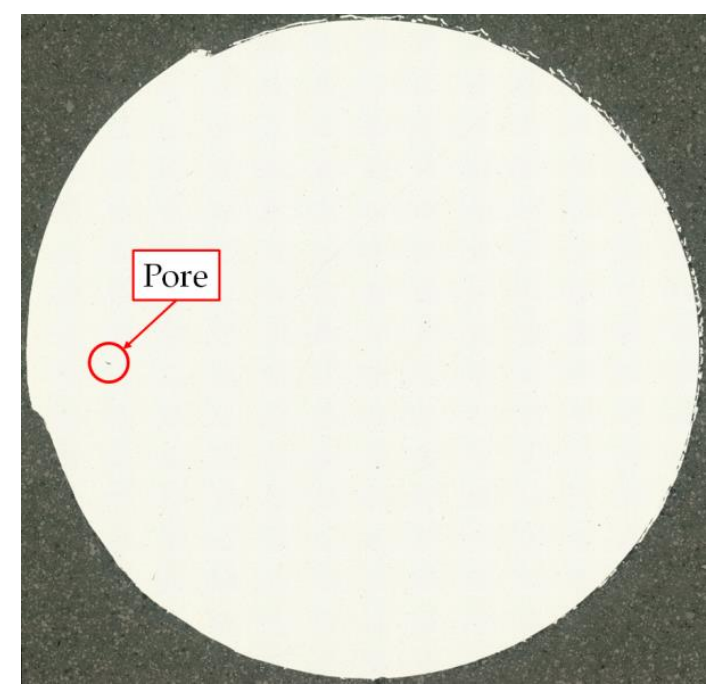

(b)

Figure 5. Micrograph of an (a) as-built and (b) HIP sample.

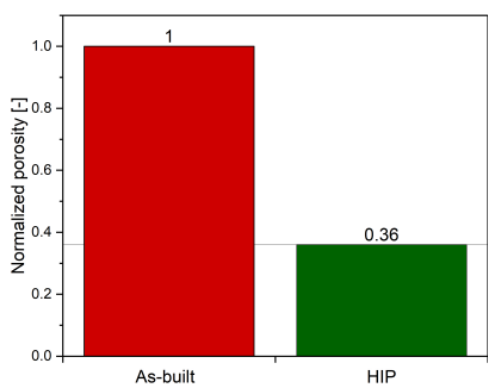

(a)

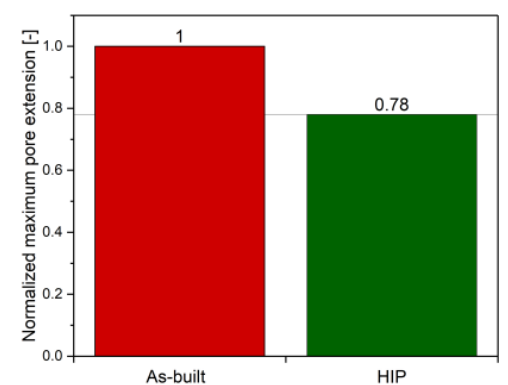

(b)

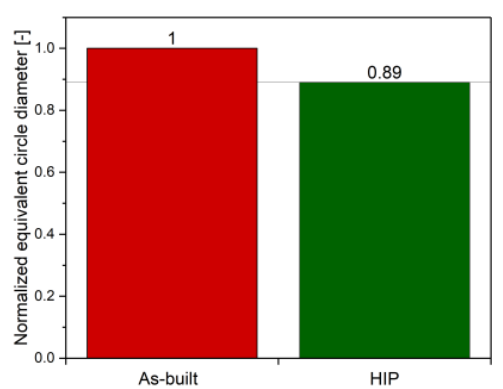

(c)

Figure 6. Difference in (a) porosity, (b) maximum pore extension, and (c) equivalent circle pore diameter between the as-built and HIP series.

Table 3. Summary of the porosity and pore size characteristics between the as-built and HIP condition.

\begin{tabular}{cccc}
\hline Condition & $\begin{array}{c}\text { Normalized Amount } \\
\text { of Porosity }\end{array}$ & $\begin{array}{c}\text { Normalized Maximum } \\
\text { Pore Extension }\end{array}$ & $\begin{array}{c}\text { Normalized Equivalent } \\
\text { Circle Diameter }\end{array}$ \\
\hline As-built & $1.00($ Basis $)$ & $1.00($ Basis $)$ & $1.00($ Basis $)$ \\
HIP-treated & $0.36(-64 \%)$ & $0.78(-22 \%)$ & $0.89(-11 \%)$ \\
\hline
\end{tabular}

To characterize the crack-initiating defect, a fracture surface analysis for each tested specimen was carried out. A fractured surface of the as-built specimen is presented in Figure 7a. The surface is visually differentiated into two sections, the oscillating crack growth regime and the burst fractured area. The defect, which was responsible for the failure, can be easily identified and evaluated. In every investigated fractured surface for the as-built condition, a pore was failure critical. An example with a marked and measured pore is given in Figure $7 \mathrm{~b}$. The size and location of the failure causing imperfection was one determining factor for the fatigue strength of the material; see also [30,31]. Therefore, an evaluation of the defect size was necessary to compare and to assess the fatigue strength of the two investigated conditions. 


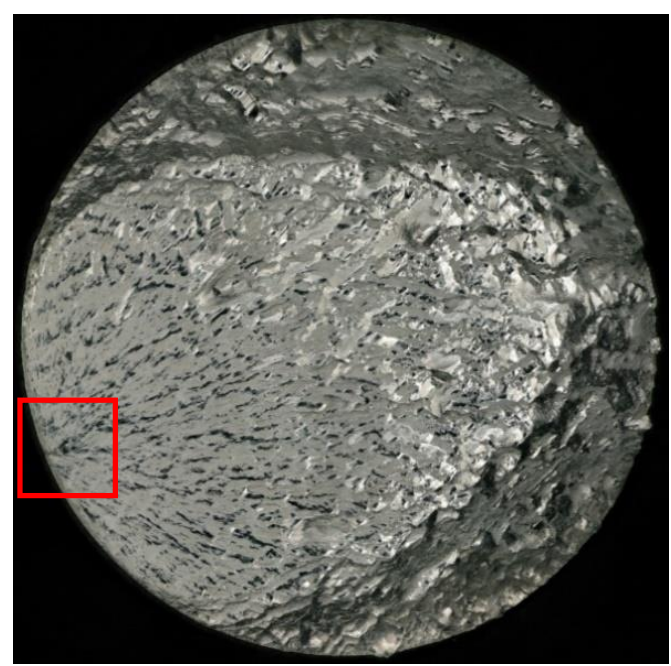

(a)

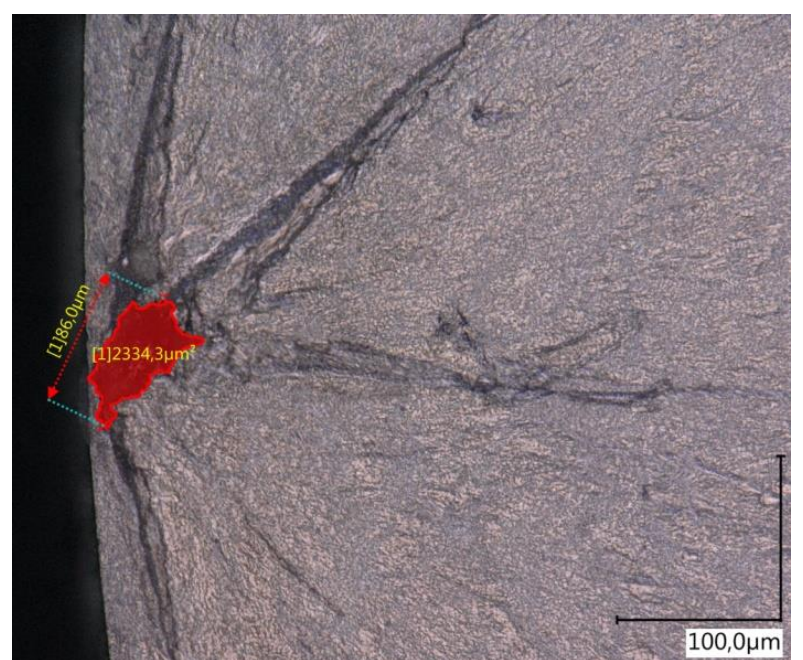

(b)

Figure 7. (a) Fracture surface of an as-built specimen; (b) size measurement of failure-critical defect.

A fracture surface for the post-processed condition (two-dimensional image with in depth focus) is displayed in Figure 8a. As pointed out for the as-built condition, the fracture surface is again separated into two different zones. The crack origin can be found within the fatigue fracture area, since the fine structured area points towards the crack initiation site. The fracture surface analysis for the HIP specimens revealed a different failure mechanism compared to the as-built ones. Due to the remarkable decrease in porosity, cavities were no longer responsible for fatigue crack initiation, but rather microstructural features such as silicon-rich phases. In Figure 8b, one can identify the debonding of Si-crystals as the failure origin; see also [26]. The crack initiated near the subsurface at all tested samples, for the HIP condition, as well as for the as-built condition. In almost every case, no evidence of pores could be found near the crack origin.

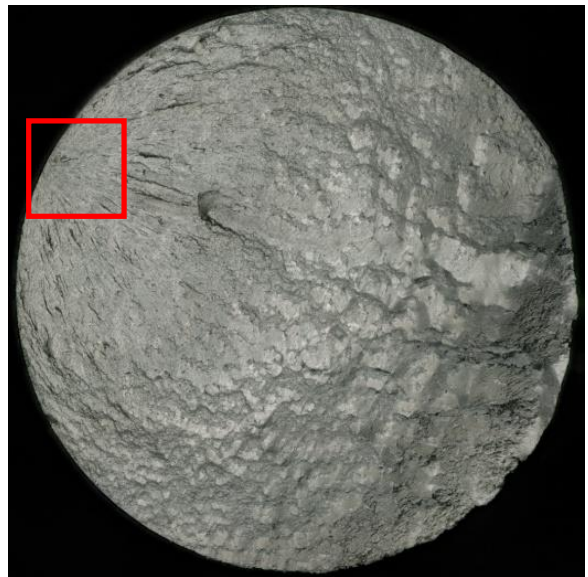

(a)

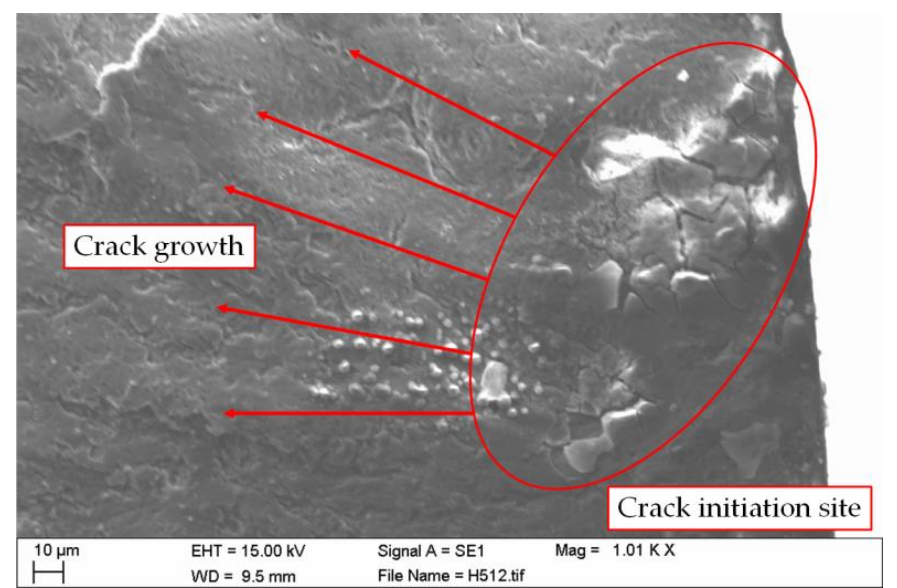

(b)

Figure 8. (a) Fracture surface of an HIP specimen; (b) failure-critical, microstructural inhomogeneity.

\section{Conclusions}

Based on the results presented in this paper, a beneficial effect on the fatigue strength of an HIP treatment above the solubility temperature with subsequent low temperature annealing can be observed for the additively-manufactured AlSi10Mg material. Concerning the microstructure, there was a significant decrease in porosity by $64 \%$, maximum pore extension by $22 \%$, and equivalent circle diameter by $11 \%$. Because of the heat influence, melt-pool boundaries were dissolved, and grain boundaries were no longer visible due to the growth of Si-precipitates at the cellular boundaries. 
After finishing the post-treatment, silicon agglomerations, as well as needle-shaped, iron-rich intermetallic phases were formed. These precipitates caused a deceleration of the crack growth due to the interference of the crack front at these microstructural features. Such a microstructure generally improves the resistance against fatigue crack growth since the propagation of the crack is obstructed. In summary, it was observed that the changes of the microstructure due to the application of the post-treatment contributed to an enhanced fatigue strength.

In addition, a change of the failure mechanism was also detected. For the as-built condition, pores were the decisive defect type. On the contrary, intermetallic inhomogeneities provoked the failure for the HIP condition. The crack initiation site is found in every case within the surface near region, independent of the failure mode. The combination of the microstructural changes consequently influenced the crack initiation, as well as the propagation behavior, leading to an improvement of $14 \%$ of the high cycle fatigue strength at a survival probability of $50 \%$ by the applied post-treatment.

Author Contributions: Conceptualization, W.S. and M.L.; methodology, W.S and M.L.; validation, W.S. and M.L.; formal analysis, W.S.; investigation, W.S. and S.S.; resources, W.S.; data curation, W.S. and S.S.; writing, original draft preparation, W.S.; writing, review and editing, W.S. and M.L.; visualization, W.S.; supervision, M.L.; project administration, M.L. and F.G.

Conflicts of Interest: The funders had no role in the design of the study; in the collection, analyses, or interpretation of data; in the writing of the manuscript; nor in the decision to publish the results.

\section{References}

1. Harun, W.; Kamariah, M.; Muhamad, N.; Ghani, S.; Ahmad, F.; Mohamed, Z. A review of powder additive manufacturing processes for metallic biomaterials. Powder Technol. 2018, 327, 128-151. [CrossRef]

2. Hedayati, R.; Hosseini-Toudeshky, H.; Sadighi, M.; Mohammadi-Aghdam, M.; Zadpoor, A.A. Computational prediction of the fatigue behavior of additively manufactured porous metallic biomaterials. Int. J. Fatigue 2016, 84, 67-79. [CrossRef]

3. Huynh, L.; Rotella, J.; Sangid, M.D. Fatigue behavior of IN718 microtrusses produced via additive manufacturing. Mater. Des. 2016, 105, 278-289. [CrossRef]

4. Leary, M.; Mazur, M.; Elambasseril, J.; McMillan, M.; Chirent, T.; Sun, Y.; Qian, M.; Easton, M.; Brandt, M. Selective laser melting (SLM) of AlSi12Mg lattice structures. Mater. Des. 2016, 98, 344-357. [CrossRef]

5. Watson, J.K.; Taminger, K. A decision-support model for selecting additive manufacturing versus subtractive manufacturing based on energy consumption. J. Clean. Prod. 2018, 176, 1316-1322. [CrossRef]

6. Herzog, D.; Seyda, V.; Wycisk, E.; Emmelmann, C. Additive manufacturing of metals. Acta Mater. 2016, 117, 371-392. [CrossRef]

7. Campbell, G.; Lahey, R. A survey of serious aircraft accidents involving fatigue fracture. Int. J. Fatigue 1984, 6, 25-30. [CrossRef]

8. Uzan, N.E.; Shneck, R.; Yeheskel, O.; Frage, N. Fatigue of AlSi10Mg specimens fabricated by additive manufacturing selective laser melting (AM-SLM). Mater. Sci. Eng. A 2017, 704, 229-237. [CrossRef]

9. Aboulkhair, N.T.; Maskery, I.; Tuck, C.; Ashcroft, I.; Everitt, N.M. Improving the fatigue behaviour of a selectively laser melted aluminium alloy: Influence of heat treatment and surface quality. Mater. Des. 2016, 104, 174-182. [CrossRef]

10. Domfang Ngnekou, J.N.; Nadot, Y.; Henaff, G.; Nicolai, J.; Kan, W.H.; Cairney, J.M.; Ridosz, L. Fatigue properties of AlSi10Mg produced by Additive Layer Manufacturing. Int. J. Fatigue 2019, 119, 160-172. [CrossRef]

11. Buffiere, J.-Y. Fatigue Crack Initiation and Propagation from Defects in Metals: Is 3D Characterization Important? Procedia Struct. Integr. 2017, 7, 27-32. [CrossRef]

12. Domfang Ngnekou, J.N.; Nadot, Y.; Henaff, G.; Nicolai, J.; Ridosz, L. Influence of defect size on the fatigue resistance of AlSi10Mg alloy elaborated by selective laser melting (SLM). Procedia Struct. Integr. 2017, 7, 75-83. [CrossRef]

13. Ceschini, L.; Morri, A.; Sambogna, G. The effect of hot isostatic pressing on the fatigue behaviour of sand-cast A356-T6 and A204-T6 aluminum alloys. J. Mater. Process. Technol. 2008, 204, 231-238. [CrossRef] 
14. Lee, M.H.; Kim, J.J.; Kim, K.H.; Kim, N.J.; Lee, S.; Lee, E.W. Effects of HIPping on high-cycle fatigue properties of investment cast A356 aluminum alloys. Mater. Sci. Eng. A 2003, 340, 123-129. [CrossRef]

15. Wang, Q.; Apelian, D.; Lados, D. Fatigue behavior of A356/357 aluminum cast alloys. Part II-Effect of microstructural constituents. J. Light Met. 2001, 1, 85-97. [CrossRef]

16. Wang, Q.; Apelian, D.; Lados, D. Fatigue behavior of A356-T6 aluminum cast alloys. Part I. Effect of casting defects. J. Light Met. 2001, 1, 73-84. [CrossRef]

17. Beretta, S.; Romano, S. A comparison of fatigue strength sensitivity to defects for materials manufactured by AM or traditional processes. Int. J. Fatigue 2017, 94, 178-191. [CrossRef]

18. Brandl, E.; Heckenberger, U.; Holzinger, V.; Buchbinder, D. Additive manufactured AlSi10Mg samples using Selective Laser Melting (SLM): Microstructure, high cycle fatigue, and fracture behavior. Mater. Des. 2012, 34, 159-169. [CrossRef]

19. European Committee for Standardization (CEN). Aluminium and Aluminium Alloys—Castings—Chemical Composition and Mechanical Properties; CEN: Brussels, Belgium, 2010.

20. Gänser, H.-P.; Maierhofer, J.; Christiner, T. Statistical correction for reinserted runouts in fatigue testing. Int. J. Fatigue 2015, 80, 76-80. [CrossRef]

21. Ngnekou, J.N.D.; Henaff, G.; Nadot, Y.; Nicolai, J.; Ridosz, L. Fatigue resistance of selectively laser melted aluminum alloy under T6 heat treatment. Procedia Eng. 2018, 213, 79-88. [CrossRef]

22. Li, W.; Li, S.; Liu, J.; Zhang, A.; Zhou, Y.; Wei, Q.; Yan, C.; Shi, Y. Effect of heat treatment on AlSi10Mg alloy fabricated by selective laser melting: Microstructure evolution, mechanical properties and fracture mechanism. Mater. Sci. Eng. A 2016, 663, 116-125. [CrossRef]

23. Prashanth, K.G.; Scudino, S.; Klauss, H.J.; Surreddi, K.B.; Löber, L.; Wang, Z.; Chaubey, A.K.; Kühn, U.; Eckert, J. Microstructure and mechanical properties of Al-12Si produced by selective laser melting: Effect of heat treatment. Mater. Sci. Eng. A 2014, 590, 153-160. [CrossRef]

24. Takata, N.; Kodaira, H.; Sekizawa, K.; Suzuki, A.; Kobashi, M. Change in microstructure of selectively laser melted AlSi10Mg alloy with heat treatments. Mater. Sci. Eng. A 2017, 704, 218-228. [CrossRef]

25. Zhang, C.; Zhu, H.; Liao, H.; Cheng, Y.; Hu, Z.; Zeng, X. Effect of heat treatments on fatigue property of selective laser melting AlSi10Mg. Int. J. Fatigue 2018, 116, 513-522. [CrossRef]

26. Gall, K.; Yang, N.; Horstemeyer, M.; McDowell, D.L.; Fan, J. The debonding and fracture of Si particles during the fatigue of a cast Al-Si alloy. Met. Mat. Trans. A 1999, 30, 3079-3088. [CrossRef]

27. ASTM International. Standard Practice for Statistical Analysis of Linear or Linearized Stress-Life (S-N) and Strain-Life ( $\varepsilon-N)$ Fatigue Data; ASTM International: West Conshohocken, PA, USA, 2015.

28. Dengel, D. Die arc sin $\sqrt{ }$ P-Transformation-Ein einfaches Verfahren zur grafischen und rechnerischen Auswertung geplanter Wöhlerversuche. Mater. Werkst. 1975, 6, 253-261. [CrossRef]

29. EOS GmbH-Electro Optical Systems. Data Sheet: EOS Aluminium AlSi10Mg. 2014. Available online: https://lightway-3d.de/download/LIGHTWAY_EOS_Aluminium_AlSi10Mg_de_Datenblatt.pdf (accessed on 11 December 2018).

30. Masuo, H.; Tanaka, Y.; Morokoshi, S.; Yagura, H.; Uchida, T.; Yamamoto, Y.; Murakami, Y. Effects of Defects, Surface Roughness and HIP on Fatigue Strength of Ti-6Al-4V manufactured by Additive Manufacturing. Procedia Struct. Integr. 2017, 7, 19-26. [CrossRef]

31. Romano, S.; Beretta, S.; Brandão, A.; Gumpinger, J.; Ghidini, T. HCF resistance of AlSi10Mg produced by SLM in relation to the presence of defects. Procedia Struct. Integr. 2017, 7, 101-108. [CrossRef]

(C) 2019 by the authors. Licensee MDPI, Basel, Switzerland. This article is an open access article distributed under the terms and conditions of the Creative Commons Attribution (CC BY) license (http://creativecommons.org/licenses/by/4.0/). 